\title{
BMJ Open Benefits of probiotics in preterm neonates in low-income and medium- income countries: a systematic review of randomised controlled trials
}

\author{
Girish Deshpande, ${ }^{1,2}$ Gayatri Jape, ${ }^{3,4}$ Shripada Rao, ${ }^{3,4}$ Sanjay Patole ${ }^{3}$
}

To cite: Deshpande G, Jape G, Rao $\mathrm{S}$, et al. Benefits of probiotics in preterm neonates in low-income and mediumincome countries: a systematic review of randomised controlled trials. BMJ Open 2017;7:e017638. doi:10.1136/ bmjopen-2017-017638

- Prepublication history and additional material for this paper are available online. To view these files, please visit the journal online (http://dx.doi. org/10.1136/bmjopen-2017017638).

Received 8 May 2017 Revised 10 October 2017 Accepted 11 October 2017

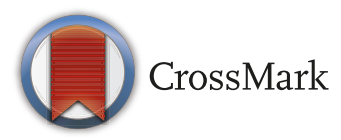

${ }^{1}$ Department of Neonatology, Nepean Hospital Sydney, Kingswood, Australia

${ }^{2}$ Sydney Medical School Nepean University of Sydney, Kingswood, NSW, Australia

${ }^{3}$ Department of Neonatal Paediatrics, KEM Hospital for Women, Subiaco, Australia ${ }^{4}$ Department of Neonatal Paediatrics, Princess Margaret Hospital for Children, Subiaco, Australia

Correspondence to Dr Sanjay Patole;

sanjay.patole@health.wa.gov.au

\section{ABSTRACT}

Objective Although there is an overall reduction in underfive mortality rate, the progress in reducing neonatal mortality rate has been very slow. Over the last 20 years, preterm births have steadily increased in low-income and medium-income countries (LMICs) particularly in sub-Saharan Africa and South Asia. Preterm birth is associated with increased mortality and morbidity, particularly in LMICs. Based on systematic reviews of randomised controlled trials (RCTs), many neonatal units in high-income countries have adopted probiotics as standard of care for preterm neonates. We aimed to systematically review the safety and efficacy of probiotics in reducing mortality and morbidity in preterm neonates in LMICs.

Design Systematic review and meta-analysis of RCTs. Data sources Medline, Embase, Cochrane Central Register of Controlled Trials, Cumulative Index of Nursing and Allied Health Literature and E-abstracts from Pediatric Academic Society meetings and other paediatric and neonatal conference proceedings were searched in January 2017

Eligibility criteria RCTs comparing probiotics versus placebo/no probiotic in preterm neonates (gestation $<37$ weeks) conducted in LMICs.

Results Total $23(n=4783)$ RCTs from 4 continents and 10 LMICs were eligible for inclusion in the meta-analysis using fixed effect model. The risk of necrotising enterocolitis (NEC greater than or equal to stage II) (risk ratio (RR) $0.46(95 \% \mathrm{Cl} 0.34$ to 0.61$)$, $\mathrm{P}<0.00001$, numbers needed to treat (NNT) 25 (95\% $\mathrm{Cl} 20$ to 50)), late-onset sepsis (LOS) (RR 0.80 (95\% Cl 0.71 to 0.91$), \mathrm{P}=0.0009$, NNT 25 (95\% $\mathrm{Cl} 17$ to 100$)$ ) and all-cause mortality (RR $0.73(95 \% \mathrm{Cl} 0.59$ to 0.90$)$, $\mathrm{P}=0.003$, NNT 50 (95\% Cl 25 to 100)) were significantly lower in probiotic supplemented neonates. The results were significant on random effects model analysis and after excluding studies with high risk of bias. No significant adverse effects were reported.

Conclusion Probiotics have significant potential to reduce mortality and morbidity (eg, NEC, LOS) in preterm neonates in LMICs.

\section{INTRODUCTION}

The Unicef 2010 report showed that the global burden of underfive mortality was

\section{Strengths and limitations of this study}

- The strengths of our systematic review include its robust methodology, comprehensive nature, large sample size and exclusive focus on randomised controlled trials (RCTs) of probiotics in preterm neonates in low-income and medium-income countries.

- The limitations include variations in the probiotic protocols in the included RCTs. Furthermore, nearly $40 \%$ of the included trials carried a high risk of bias in many domains of assessment.

reduced by one-third compared with 1990s; however progress in reducing neonatal mortality has been slow. ${ }^{1-3}$ Almost $40 \%$ of underfive deaths occur during the neonatal period and majority of these deaths occur in sub-Saharan Africa, South Asia and Oceania. An estimated $98 \%$ of all neonatal deaths occur in low-income and medium-income countries (LMICs) ${ }^{4-6}$ Out of 135 million births each year, 3.1 million have died within the neonatal period and nearly $35 \%$ of these deaths occur in preterm neonates. ${ }^{25}$ It may be perceived that prematurity is not a problem of LMICs. However, it is important to note that only $8.6 \%$ of preterm births occur in developed countries. ${ }^{5}$ Over the last 20 years, the number of preterm births has steadily increased to 9.1 million as of 2010 in the regions of sub-Saharan Africa and South Asia. Preterm birth is associated with increased risk of mortality and morbidity including late-onset sepsis (LOS), necrotising enterocolitis (NEC), feeding difficulties and long-term neurodevelopmental impairment. ${ }^{6-8}$ Although survival of preterm neonates has improved in some LMICs, morbidities such as NEC and LOS are still a major issue ${ }^{5-12}$ Considering the United Nation's (UN's) millennium developmental goal and the UN Secretary-General's Global Strategy for 
Women's and Children's Health (2010) and its accompanying 'Every Woman, Every Child initiative, Every Newborn Action plan' (ENAP), it is important to develop cost-effective simple strategies to reduce the mortality and morbidity associated with prematurity in LMICs. ${ }^{13}$

WHO defines probiotics as 'live micro-organisms which when administered in adequate amounts confer a health benefit on the host'. ${ }^{14}$ Probiotics have been shown to significantly reduce the risk of NEC, all-cause mortality, LOS and facilitate feed tolerance in preterm very low birth weight (VLBW) neonates. ${ }^{15-17}$ The mechanisms of benefits of probiotics include gut barrier enhancement, immune response modulation (eg, TLR4 receptor, nuclear factor-B, inflammatory cytokines) and direct inhibition of gut colonisation by pathogens. ${ }^{18-22}$ Many developed countries are already using probiotics routinely in preterm neonates for prevention of NEC. ${ }^{23-32}$ It has been suggested that probiotics may have a role in LMICs for prevention, treatment of acute gastrointestinal diseases, particularly in children with HIV infection. ${ }^{33-36}$ Given their simplicity and affordability, we aimed to systematically review the safety and efficacy of probiotics in reducing the risk of mortality and morbidity in preterm neonates in LMICs.

\section{METHODS}

Guidelines from the Cochrane Neonatal Review Group (http:// neonatal.cochrane.org/resources-reviewauthors), ${ }^{37}$ Centre for Reviews and Dissemination (http://www.york.ac.uk/crd/guidance/) ${ }^{38}$ and the Preferred Reporting Items for Systematic Reviews and Meta-Analyses statement ${ }^{39}$ were followed for undertaking and reporting this systematic review and meta-analysis. Ethics approval was not required.

\section{Eligibility criteria}

\section{Types of studies}

Only randomised controlled trials (RCTs) were included in the review. Observational studies, narrative/systematic reviews, case reports, letters, editorials and commentaries were excluded but read to identify potential additional studies.

\section{Types of participants}

Preterm neonates born at a gestational age (GA) $<37$ weeks or LBW $(<2500 \mathrm{~g})$ or both (same criteria as the Cochrane review, 2014). ${ }^{15}$

\section{Setting}

Only RCTs from LMICs were included. LMICs were defined as per the World Bank guidelines which include countries with gross national income per capita of under US $\$ 12736 /$ year. $^{40}$

\section{Intervention and comparison}

Enteral administration of probiotic supplement versus control (placebo/no probiotic).

\section{Outcomes}

All-cause mortality, LOS (positive blood/cerebrospinal fluid (CSF) culture on a sample collected 48-72 hours after birth), definite NEC (stage $\geq$ II modified Bell staging) ${ }^{41}$ and time to full enteral feeds (TFEF: $120 \mathrm{~mL}$ / $\mathrm{kg} /$ day).

\section{Search strategy}

The databases Medline searched via PubMed (https:// www.ncbi.nlm.nih.gov 1966-2017), Embase (Excerpta Medica dataBASE) via Ovid (http://ovidsp.tx.ovid.com, 1980-2017), Cochrane Central Register of Controlled Trials (http://www.thecochranelibrary.com, through January 2017), Cumulative Index of Nursing and Allied Health Literature via OVID (http://ovidsp.tx.ovid.com, 1980-January 2017) and E-abstracts from the Pediatric Academic Society meetings (https://www.pas-meeting. org/about/\#past, 2000-January 2017) were searched in January 2017. Abstracts of other conference proceedings such as European Academy of Paediatric Societies and the British Maternal and Fetal Medicine Society were searched in Embase. 'Google Scholar' was searched for articles that might not have been cited in the standard medical databases. Grey literature was searched using the national technical information services (http://www. ntis.gov/), Open Grey (http://www.opengrey.eu/), and Trove (http://trove.nla.gov.au/). We have also searched Literatura Latino-Americana e do Caribe em Ciências da Saúde (LILACS) and Caribmed via the BIREME/ PAHO/WHO-Latin American and Caribbean Center on Health Sciences Information; PAHO, Pan American Health Organization (http://lilacs.bvsalud.org/en/) using broad terminologies Probiotics OR Probiotic Or Bifidobacterium OR Bifidobacteria OR Lactobacillus OR Lactobacilli OR Saccharomyces. We also searched ClinicalTrials.gov (https://clinicaltrials.gov), International Clinical Trials Registry Platform (http://www.who.int/ ictrp/en/) and BioPortfolio (https://www.bioportfolio. com) for ongoing RCTs. The reference lists of eligible studies and review articles were searched to identify additional studies. Reviewers SR, GJ and GD conducted the literature search independently. No language restriction was applied. The non-English studies were identified by reading the recent systematic reviews of probiotic supplementation for reducing the risk of $\mathrm{NEC}^{42} 43$ and from cross references of individual studies. Full texts of all non-English studies were obtained via University of Sydney and Department of New South Wales (NSW) health library. A research officer from the NSW Health, University of Sydney translated the articles. Attempts were made to contact the authors for additional data and clarification of methods. Only published data were used for those studies where available.

PubMed was searched using the following terminology: (('Infant, Newborn' [Mesh]) OR ('Infant, Extremely Premature' [Mesh] OR 'Infant, Premature' [Mesh])) OR ('Infant, Low Birth Weight' [Mesh] OR 'Infant, Extremely Low Birth Weight' [Mesh] OR 'Infant, Very 
Low Birth Weight' [Mesh])) AND 'Probiotics' [Majr]. It was also searched using (('Infant, Extremely Premature' [Mesh] OR 'Infant, Extremely Low Birth Weight' [Mesh] OR 'Infant, Very Low Birth Weight' [Mesh] OR 'Infant, Small for Gestational Age' [Mesh] OR 'Infant, Premature, Diseases' [Mesh] OR 'Infant, Premature' [Mesh] OR 'Infant, Newborn, Diseases' [Mesh] OR 'Infant, Newborn' [Mesh] OR 'Infant, Low Birth Weight' [Mesh] ) AND ((('Bifidobacterium' [Mesh]) OR 'Lactobacillus' [Mesh]) OR 'Saccharomyces' [Mesh]). The other databases were searched using similar terminologies. The detailed search terminology is given in online supplementary appendix 1 .

\section{Study selection}

The abstracts of citations obtained from the initial broad search were read independently by reviewers SR, GJ and GD to identify potentially eligible studies. Full-text articles of these studies were obtained and assessed for eligibility by reviewers SR, GJ and GD independently, using the predefined eligibility criteria. Differences in opinion were resolved by group discussion to reach consensus. Care was taken to ensure that multiple publications of the same study were excluded to avoid data duplication.

\section{Data extraction}

Reviewers GD, SR and GJ extracted the data independently using a data collection form designed for this review. Information about the study design and outcomes was verified by all reviewers. Discrepancies during the data extraction process were resolved by group discussion. We contacted authors for additional information/clarifications.

\section{Assessment of risk of bias}

Risk of bias (ROB) was assessed using the Cochrane 'Risk of Bias Assessment Tool'. ${ }^{44}$ Authors GD, SR and GJ independently assessed the ROB in all domains including random number generation, allocation concealment, blinding of intervention and outcome assessors, completeness of follow-up, selectivity of reporting and other potential sources of bias. For each domain, the ROB was assessed as low, high or unclear risk based on the Cochrane Collaboration guidelines.

\section{Data synthesis}

Meta-analysis was conducted using Review Manager 5.3 (Cochrane Collaboration, Nordic Cochrane Centre). Fixed effects model (FEM) (Mantel-Haenszel method) was used. Random effects model (REM) analysis was conducted to recheck the results if there was significant heterogeneity on FEM. Effect size was expressed as risk ratio (RR) and $95 \% \mathrm{CI}$.

Statistical heterogeneity was assessed by the $\chi^{2}$ test, $\mathrm{I}^{2}$ statistic and visual inspection of the forest plot (overlap of CIs). A $\mathrm{P}$ value $<0.1$ on $\chi^{2}$ statistic was considered to indicate heterogeneity. $\mathrm{I}^{2}$ statistic values were interpreted as per the Cochrane handbook guidelines as follows: $0 \%$ to $40 \%$-might not be important; $30 \%$ to $60 \%$-may represent moderate heterogeneity; $50 \%$ to $90 \%$-may represent substantial heterogeneity; $75 \%$ to $100 \%$-considerable heterogeneity. ${ }^{37}$ The risk of publication bias was assessed by visual inspection of the funnel plot. ${ }^{45}$

\section{Subgroup analysis}

(1) Low ROB: random sequence generation and allocation concealment; (2) preterm neonates less than 34 weeks gestation or birth weight less than $1500 \mathrm{~g}$; (3) where Bifidobacterium was part of the supplementation; (4) where Lactobacillus was part of the supplementation; (5) single strain probiotic were used and (6) multiple strain probiotics were used.

\section{Summary of findings table}

The key information concerning the quality of evidence, the magnitude of effect of the intervention and the sum of available data on the main outcome was presented in the 'summary of findings table' as per the Grades of Recommendation, Assessment, Development and Evaluation (GRADE) guidelines. ${ }^{44}$

\section{RESULTS}

The literature search retrieved 1926 potential relevant citations. After carefully reviewing the abstracts, 1814 studies were excluded: reviews: 378; observational studies: 187; commentaries: 49; case reports: 147; RCTs in adult and paediatric population: 53 and non-relevant studies: 982. Finally, 23 RCTs $(n=4783)$ conducted in 10 different LMICs in 4 continents were included in the meta-analysis. ${ }^{12} 46-67$ The search strategy results are given in online supplementary appendix 1 . The flow diagram of study selection process is given in figure 1. The characteristics of the included studies are given in table 1 . Out of the 23 included studies, single-strain probiotics were used in 11 studies, whereas 12 used multiple strains. Lactobacillus was part of the supplementation in 13 studies; Bifidobacterium was part of the supplementation in 11 studies and saccharomyces in 3 studies (table 1).

\section{ROB of included studies}

A total of $14 / 23(60 \%)$ included studies were judged to have low ROB for the domain of 'random sequence generation', and (56\%) were considered to have low ROB for 'allocation concealment' (table 2).

\section{Effect of probiotics on $\geq$ Stage II (definite) NEC}

Data on definite NEC was reported by 20 trials $(\mathrm{n}=4022) .{ }^{12} \quad 46-53 \quad 55 \quad 56 \quad 58-65 \quad 67$ A higher proportion of neonates in the control group developed definite NEC compared with the probiotic group $(65 / 2065(3.1 \%)$ vs $135 / 1957(6.9 \%))$. Meta-analysis using a FEM estimated a lower risk (RR 0.46 (95\% CI 0.34 to 0.61$), \mathrm{P}<0.00001$ ) of NEC in the probiotic group. There was no significant heterogeneity $\left(\mathrm{I}^{2}=19 \%, \mathrm{P}=0.22\right)$ among the trials. The numbers needed to treat (NNT) with probiotics to prevent one case of NEC was 25 (95\% CI 20 to 50; figure 2). 

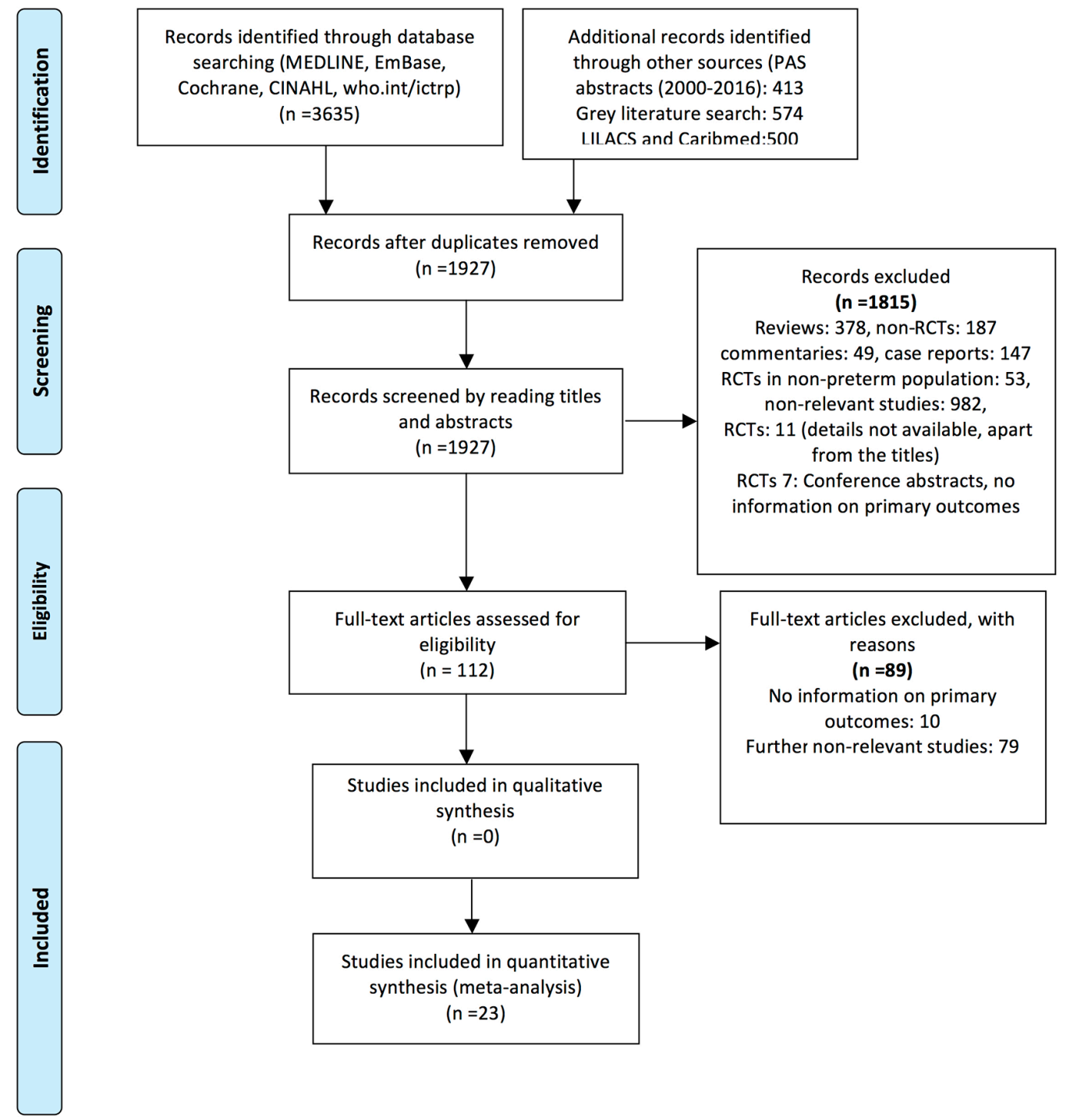

Figure 1 Flow diagram of search strategy and study selection (January 2017). CINAHL, Cumulative Index of Nursing and Allied Health Literature; LILACS, Literatura Latino-Americana e do Caribe em Ciências da Saúde; PAS, Pediatric Academy Society; $\mathrm{RCT}$, randomised controlled trial.

\section{Effect of probiotics on LOS}

Data from 18 trials $^{12} 464749$ 51-54 56-62 $646567 \quad(\mathrm{n}=4062)$ showed that a higher proportion of neonates in the control group developed LOS compared with those in the probiotic group (308/2076 (14.5\%) vs 358/1986 $(18 \%))$. Meta-analysis using a FEM estimated a lower risk (RR 0.80 (95\% CI 0.71 to 0.91 ), $\mathrm{P}=0.0009$ ) of LOS in the probiotic group. There was no significant heterogeneity $\left(\mathrm{I}^{2}=25 \% ; \mathrm{P}=0.16\right)$ among the trials. The NNT with probiotics to prevent one case of LOS was 25 (95\% CI 17 to 50; figure 3).

\section{Effect of probiotics on all-cause mortality}

Data from 19 trials $(\mathrm{n}=4196),{ }^{12}$ 46-49 51-54 56-65 showed reduced risk of death due to all causes in the probiotic versus control group (137/2148 (6.37\%) vs 176/2048 $(8.59 \%))$. Meta-analysis using a FEM estimated a lower risk (RR 0.73 (95\% CI 0.59 to 0.90 ), $\mathrm{P}=0.003$ ) of death in the probiotic group. No significant heterogeneity was noted between the trials $\left(\mathrm{I}^{2}=0 \% ; \mathrm{P}=0.67\right)$. The NNT to prevent one death by probiotic supplement was $50(95 \%$ CI 25 to 100; figure 4).

\section{Effect of probiotics on TFEF}

Meta-analysis of data $(\mathrm{n}=2154)$ from 13 trials $1247-49535659-636566$ showed significant reduction in TFEF in the probiotics versus control group ( $\mathrm{MD}=-3.09$ days (95\% CI: -3.49 to -2.69$), \mathrm{P}<0.00001)$. However, there was significant heterogeneity $\left(\mathrm{I}^{2}=90 \%, \mathrm{P}<0.00001\right)$ among the trials. These results were hence checked by using REM and remained significant $(\mathrm{MD}=-1.95$ days $(95 \% \mathrm{CI}:-3.44$ to -0.45$), \mathrm{P}=0.01$; figure 5 ). $\mathrm{MD}$, mean difference.

\section{Subgroup analysis}

The beneficial effects continued to be observed in studies: (1) low ROB: random sequence generation and allocation concealment (table 3); (2) that only included infants with gestational age $<34$ weeks or birth weight 


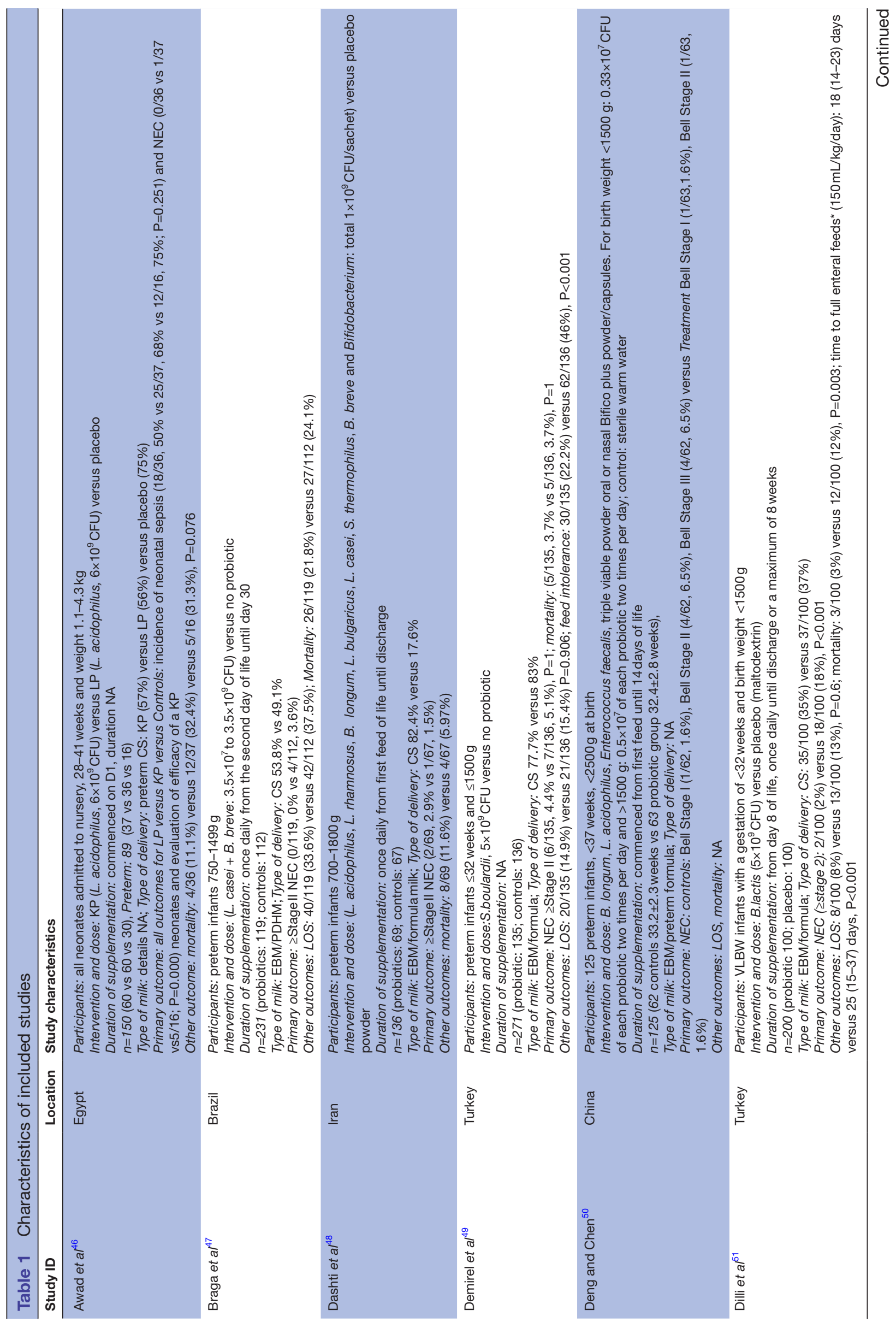




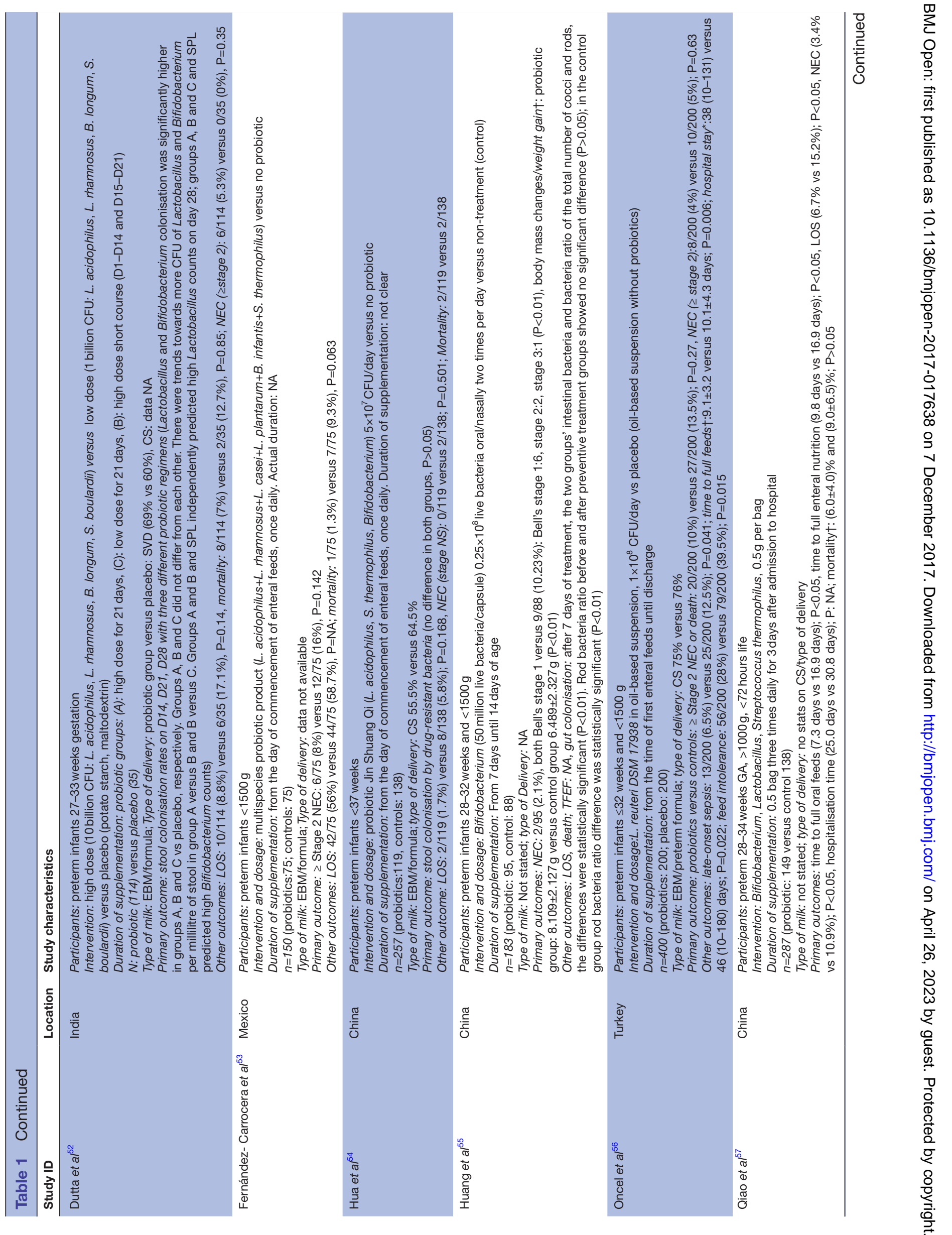




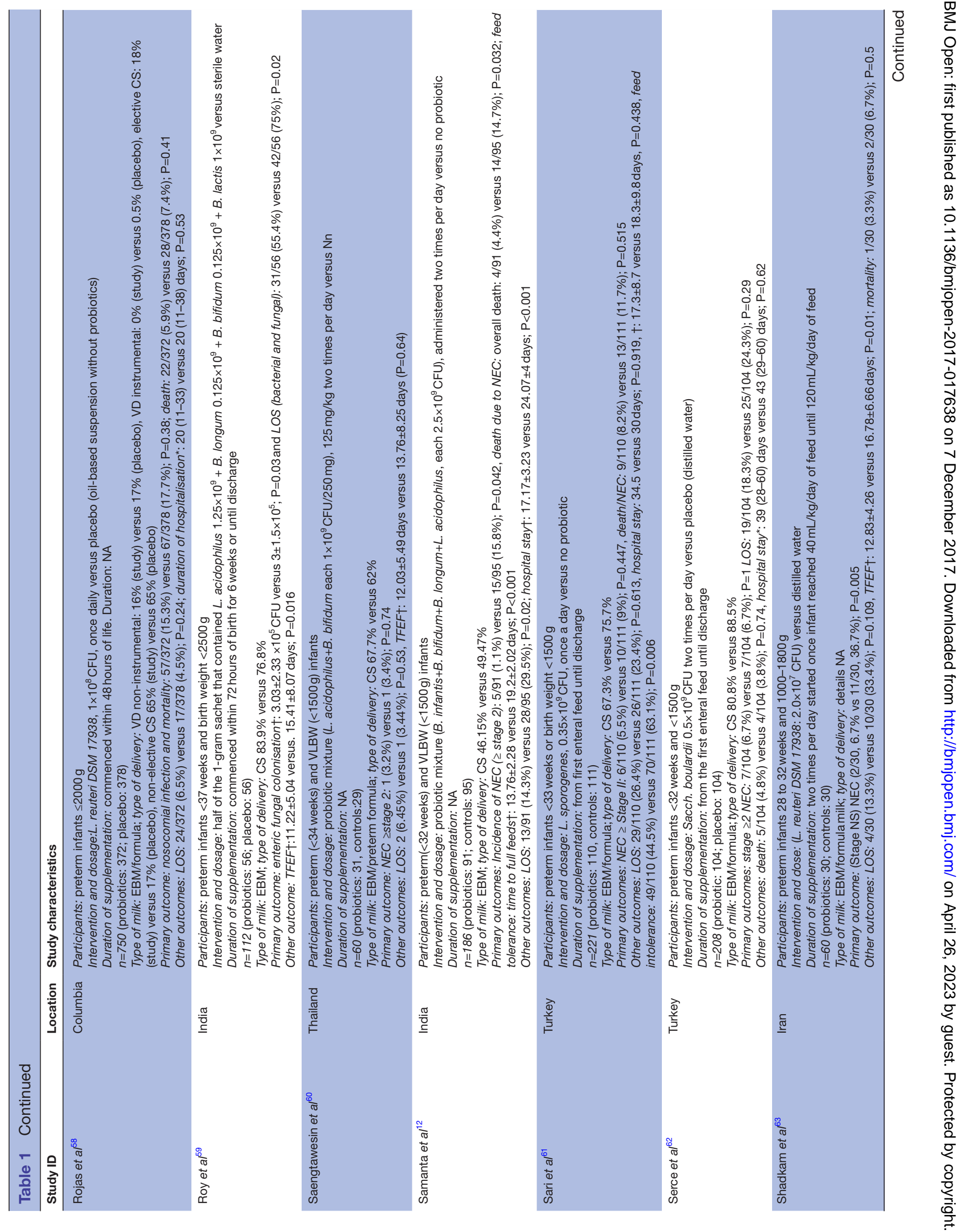



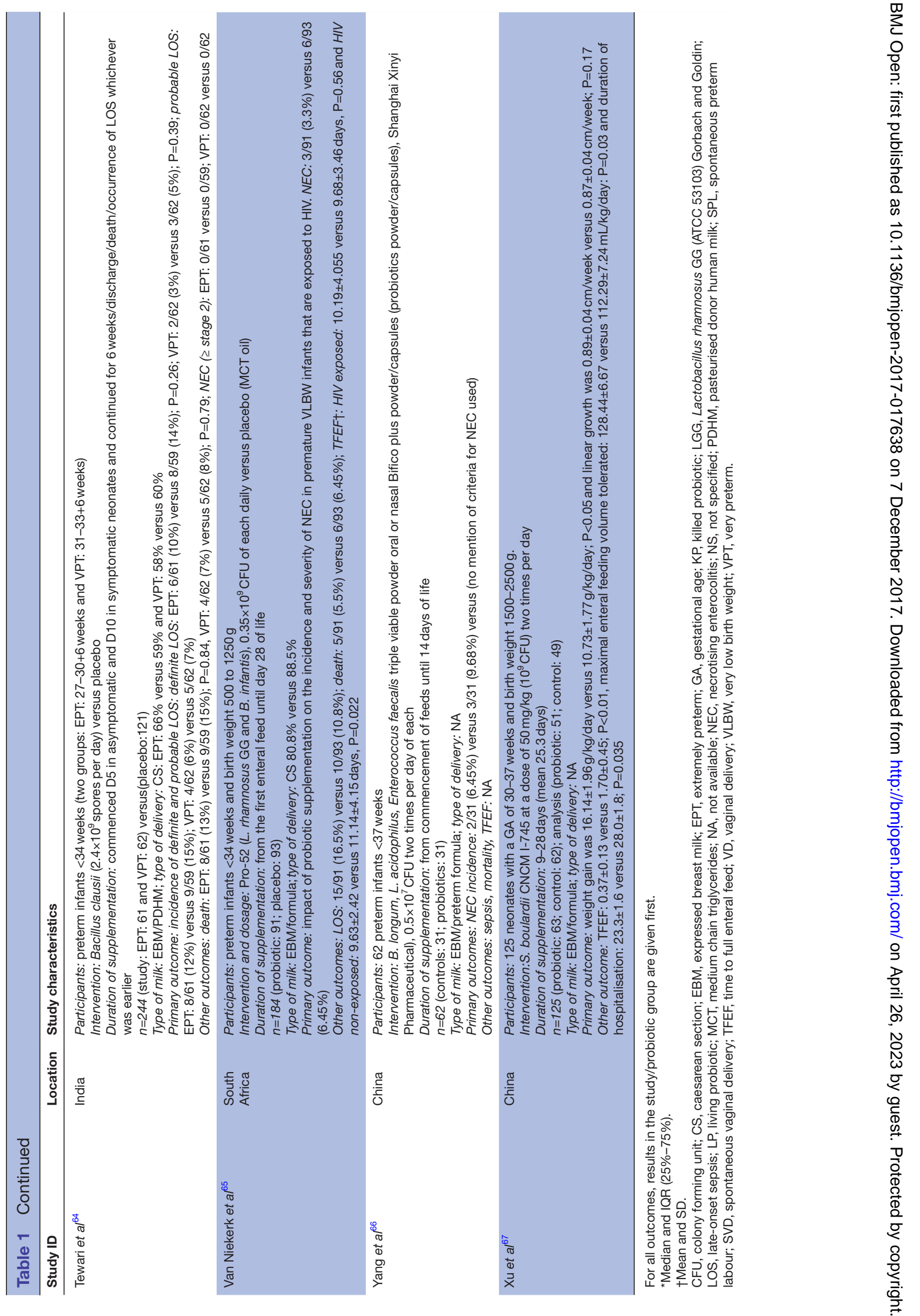


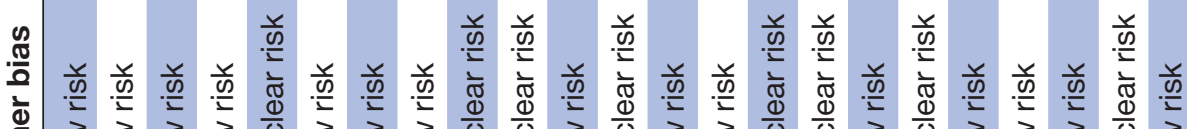
离

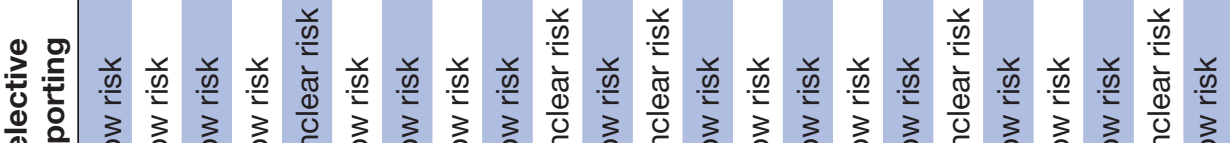

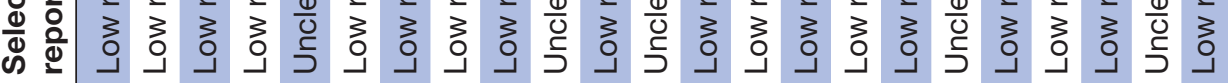

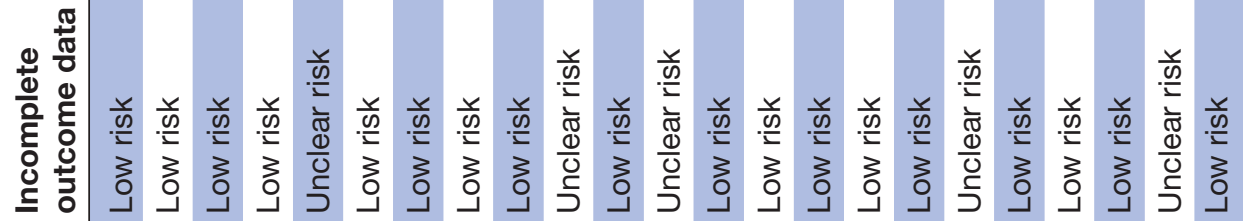

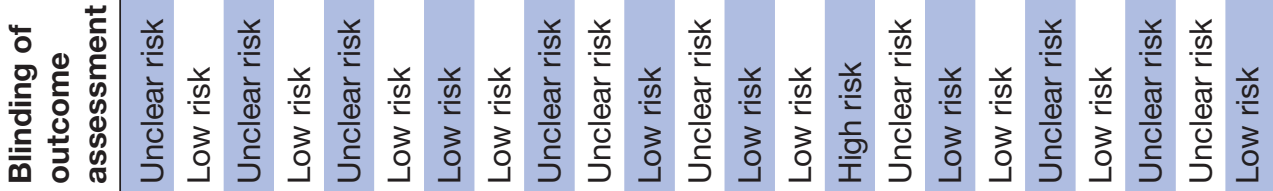

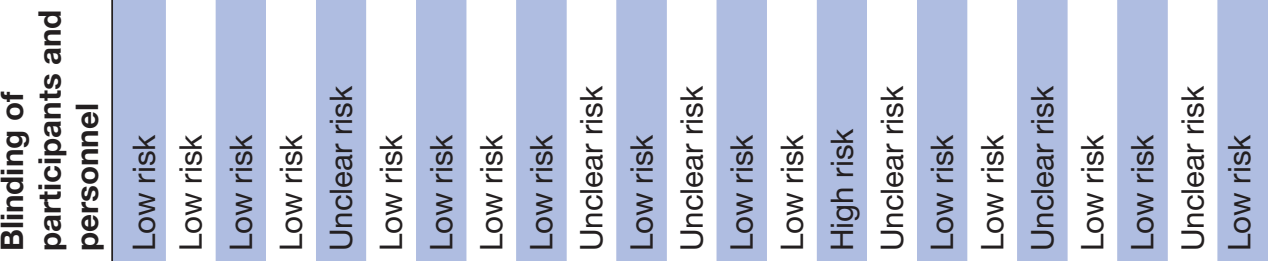

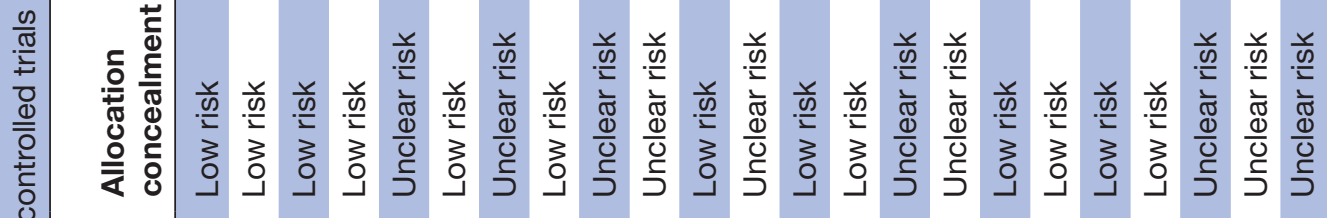

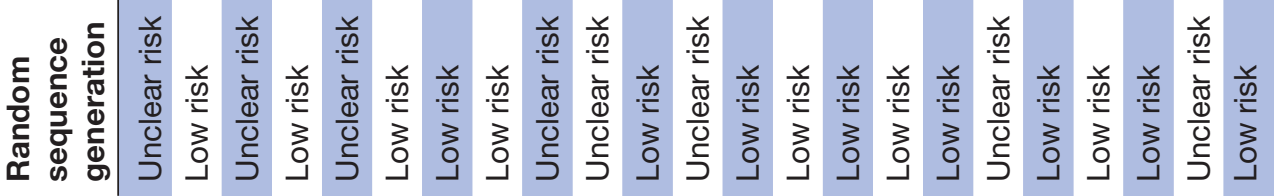

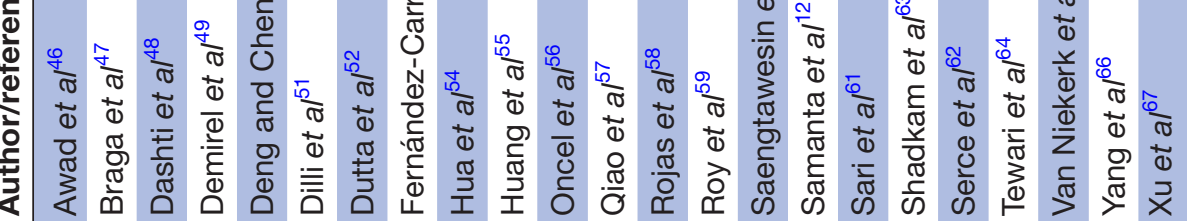




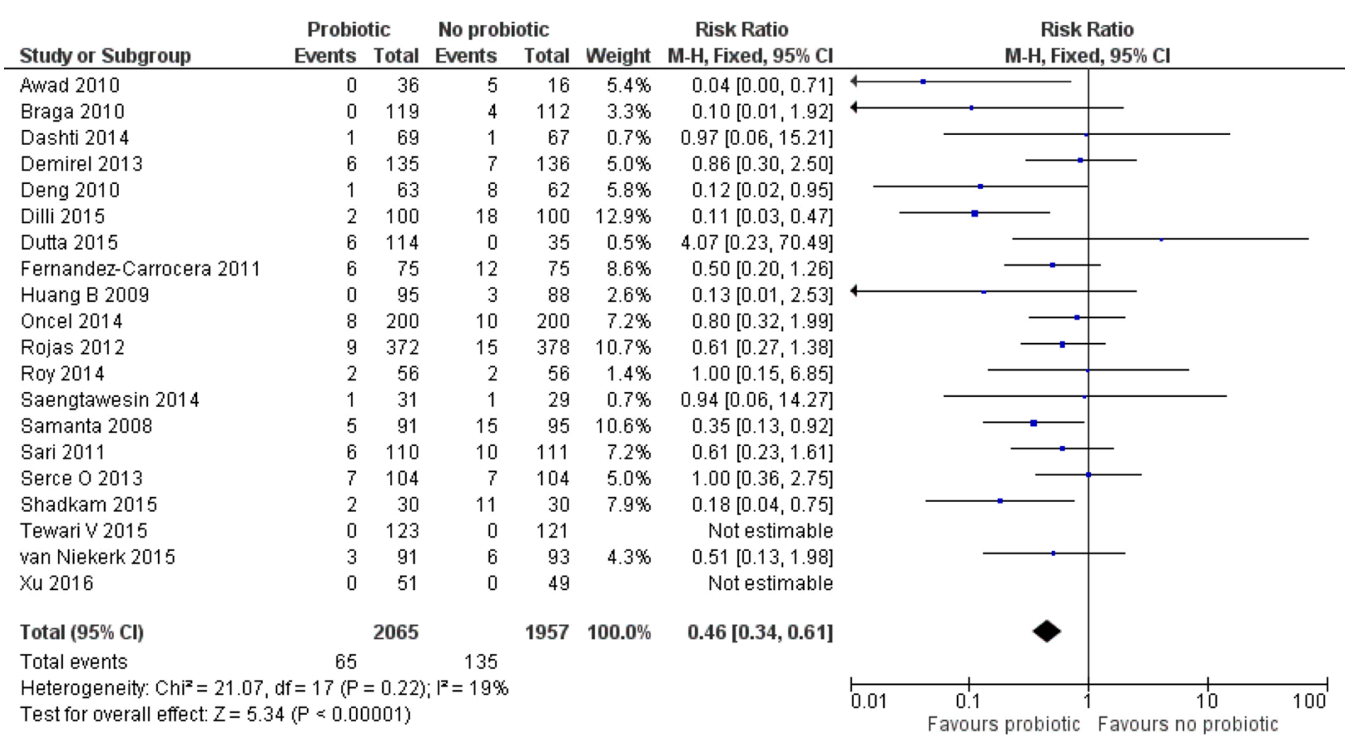

Figure 2 Forest plot: effect of probiotics on definite ( $\geq$ Stage II) necrotising enterocolitis.

$<1500 \mathrm{~g}$; (3) where Bifidobacterium was part of the supplementation; (4) where Lactobacillus was part of the supplementation; (5) single strain probiotics were used and (6) multiple strain supplements were used; however, on REM meta-analysis, statistical significance was lost for some of these analyses (table 4). The overall evidence according to GRADE guidelines is provided as a summary of findings table (table 5). The evidence was deemed high in view of the large sample size, low risk of bias in majority $(14 / 20)$ of the included studies, narrow CIs around the effect size estimate, very low $\mathrm{P}$ value for effect size estimate and mild statistical heterogeneity. Visual inspection of the funnel plot suggested that there was no publication bias (figure 6).

\section{Safety}

None of the studies reported any significant adverse effects including probiotic sepsis.

\section{DISCUSSION}

The results of our systematic review of 23 RCTs $(n=4783$ ) conducted in 10 LMICs across 4 continents show that probiotic supplementation in preterm neonates (born $<37$ weeks) significantly reduces the risk of all-cause mortality, LOS and NEC in such a set-up. The limitations of this review include variations in types of probiotics used in different studies and limitations of study qualities in few studies. The strengths of our systematic review include its robust methodology, comprehensive nature and exclusive focus on RCTs of probiotics in preterm neonates in LMICs. The limitations of our review include the variations in the probiotic protocols in the included RCTs, and the fact that nearly $40 \%$ of the included trials carried a high risk of bias in many domains of assessment.

To our knowledge, this is the first systematic review focusing on RCTs of probiotics in preterm neonates in LMICs. The summary findings as per GRADE guidelines

Figure 3 Forest plot: effect of probiotics on late-onset sepsis. 


\begin{tabular}{|c|c|c|c|c|c|}
\hline \multirow[b]{2}{*}{ Study or Subgroup } & \multicolumn{2}{|c|}{ Probiotic } & \multicolumn{2}{|c|}{ No probiotic } & \multirow[b]{2}{*}{ Weight } \\
\hline & Events & Total & Events & Total & \\
\hline Awad 2010 & 5 & 60 & 6 & 30 & $4.5 \%$ \\
\hline Braga 2010 & 26 & 119 & 27 & 112 & $15.5 \%$ \\
\hline Dashti 2014 & 8 & 69 & 4 & 67 & $2.3 \%$ \\
\hline Demirel 2013 & 5 & 135 & 5 & 136 & $2.8 \%$ \\
\hline Dilli 2015 & 3 & 100 & 12 & 100 & $6.7 \%$ \\
\hline Dutta 2015 & 8 & 114 & 2 & 35 & $1.7 \%$ \\
\hline Fernandez-Carrocera 2011 & 1 & 75 & 7 & 75 & $3.9 \%$ \\
\hline Hua 2014 & 2 & 119 & 3 & 138 & $1.5 \%$ \\
\hline Oncel 2014 & 15 & 200 & 20 & 200 & $11.1 \%$ \\
\hline Qiao 2012 & 6 & 149 & 9 & 138 & $5.2 \%$ \\
\hline Rojas 2012 & 22 & 372 & 28 & 378 & $15.5 \%$ \\
\hline Roy 2014 & 7 & 56 & 8 & 56 & $4.5 \%$ \\
\hline Saengtawesin 2014 & 0 & 31 & 0 & 29 & \\
\hline Samanta 2008 & 4 & 91 & 14 & 95 & $7.6 \%$ \\
\hline Sari 2011 & 3 & 110 & 4 & 111 & $2.2 \%$ \\
\hline Serce 02013 & 4 & 104 & 5 & 104 & $2.8 \%$ \\
\hline Shadkam 2015 & 1 & 30 & 2 & 30 & $1.1 \%$ \\
\hline Tewari V 2015 & 12 & 123 & 14 & 121 & $7.9 \%$ \\
\hline van Niekerk 2015 & 5 & 91 & 6 & 93 & $3.3 \%$ \\
\hline Total $(95 \% \mathrm{Cl})$ & & 2148 & & 2048 & $100.0 \%$ \\
\hline Total events & 137 & & 176 & & \\
\hline Heterogeneity: $\mathrm{Chi}^{2}=13.9$ & $=17(\mathrm{P}=$ & $=0.67) ;$ & $; 1^{2}=0 \%$ & & \\
\hline
\end{tabular}

Risk Ratio Risk Ratio

, Fixed, 95\% Cl

$0.42[0.14,1.26]$

$0.91[0.56,1.45]$

$1.94[0.61,6.15]$

$1.01[0.30,3.40]$

$0.25[0.07,0.86]$

$1.23[0.27,5.52]$

$0.14[0.02,1.13]$

$0.77[0.13,4.55]$

$0.75[0.40,1.42]$

$0.62[0.23,1.69]$

$0.80[0.47,1.37]$

$0.88[0.34,2.25]$

Not estimable

$0.30[0.10,0.87]$

$0.76[0.17,3.30]$

$0.80[0.22,2.90]$

$0.50[0.05,5.22]$

$0.84[0.41,1.75]$

$0.85[0.27,2.69]$

$0.73[0.59,0.90]$

M-H, Fixed, 95\% C

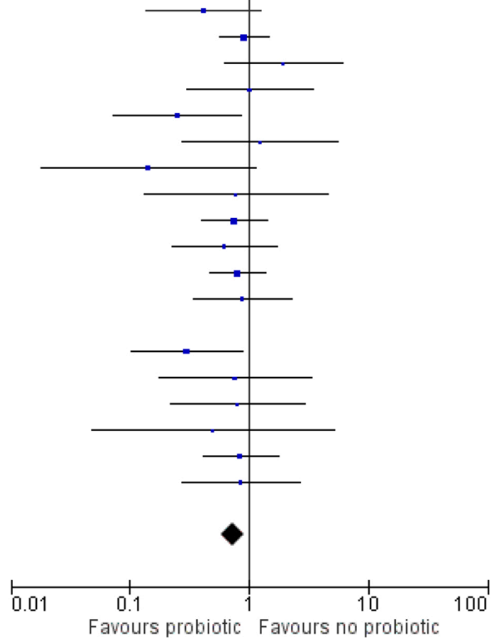

confirm the high-quality evidence it provides (table 5). Our results are significant considering the UN's MDG4 and UN Secretary-General's Global Strategy for Women's and Children's Health (2010) and its accompanying Every Woman, Every Child initiative, ENAP and the burden of prematurity in LMICs. ${ }^{4513}$

The incidence of prematurity is significantly increasing in LMICs compared with Europe or North America. There are issues related to reporting of preterm births and outcomes in LMICs. ${ }^{68}$ However, the studies funded by the WHO estimate 13 million preterm births/year in LMICs with 11 million (85\%) of these being concentrated in Africa and Asia, $\sim 0.5$ million each in Europe and North America (excluding Mexico) and 0.9 million in Latin America and the Caribbean. ${ }^{69}$ The highest rates $(11.9 \%)$ and number (seven million) of preterm births were in Africa and Asia, respectively. Mortality and morbidities such as LOS, NEC and feeding difficulties are major issues in preterm neonates. Although specific data from LMICs is not available, approximately onemillion preterm neonates die every year, predominantly due to sepsis, and long-term impairment in survivors is becoming an important issue. ${ }^{70}$

Consistent with our recent systematic review, ${ }^{71}$ our results show that probiotics reduced the risk of NEC and

all-cause mortality and of LOS in preterm neonates. (RR 0.81 ( $95 \%$ CI 0.71 to 0.92 ), $\mathrm{P}=0.001$ ). The reduction of LOS by probiotics is important considering that neonatal sepsis is responsible for nearly a third all neonatal deaths in LMICs. ${ }^{19} 202272-77$

It is important to note that the burden of NEC is as significant in LMICs as in high-income countries. The incidence and severity of NEC is higher in LMICs and includes up to $15 \%$ cases of NEC totalis with $\sim 100 \%$ mortality. ${ }^{9}$ It occurs in VLBW and ELBW neonates and in preterm neonates with higher birth weight. Lack of antenatal steroids and being small for gestational age (SGA) due to intrauterine growth restriction (IUGR) are known risk factors for NEC. ${ }^{78}$ The reason for higher incidence of NEC in LMICs could include the higher numbers of preterm 'SGA-IUGR' births and limited coverage of antenatal steroids. ${ }^{79} 80$ The NEC-related mortality and morbidity is almost entirely due to progression of the illness from stage II to stage III. Management of surgical NEC is difficult in LMICs considering the limited resources. Primary prevention of NEC is therefore an important strategy for reducing the health burden of the condition in LMICs. Considering the effect size with regards to reduced risk of NEC, the benefits of probiotics in LMICs could not be overemphasised.

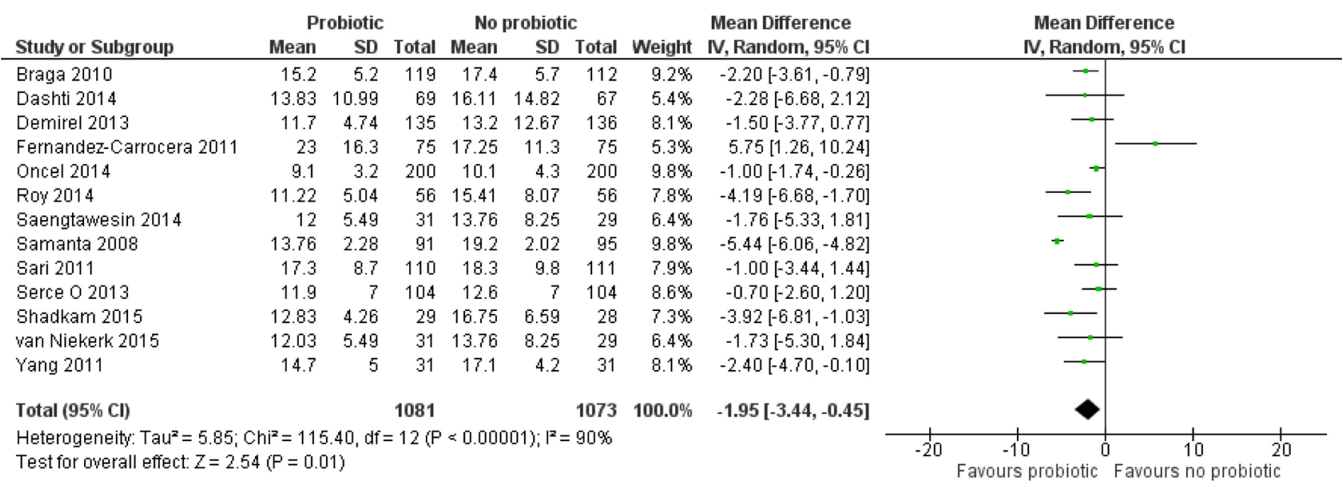

Figure 5 Forest plot: effect of probiotics on time to full enteral feeds. 

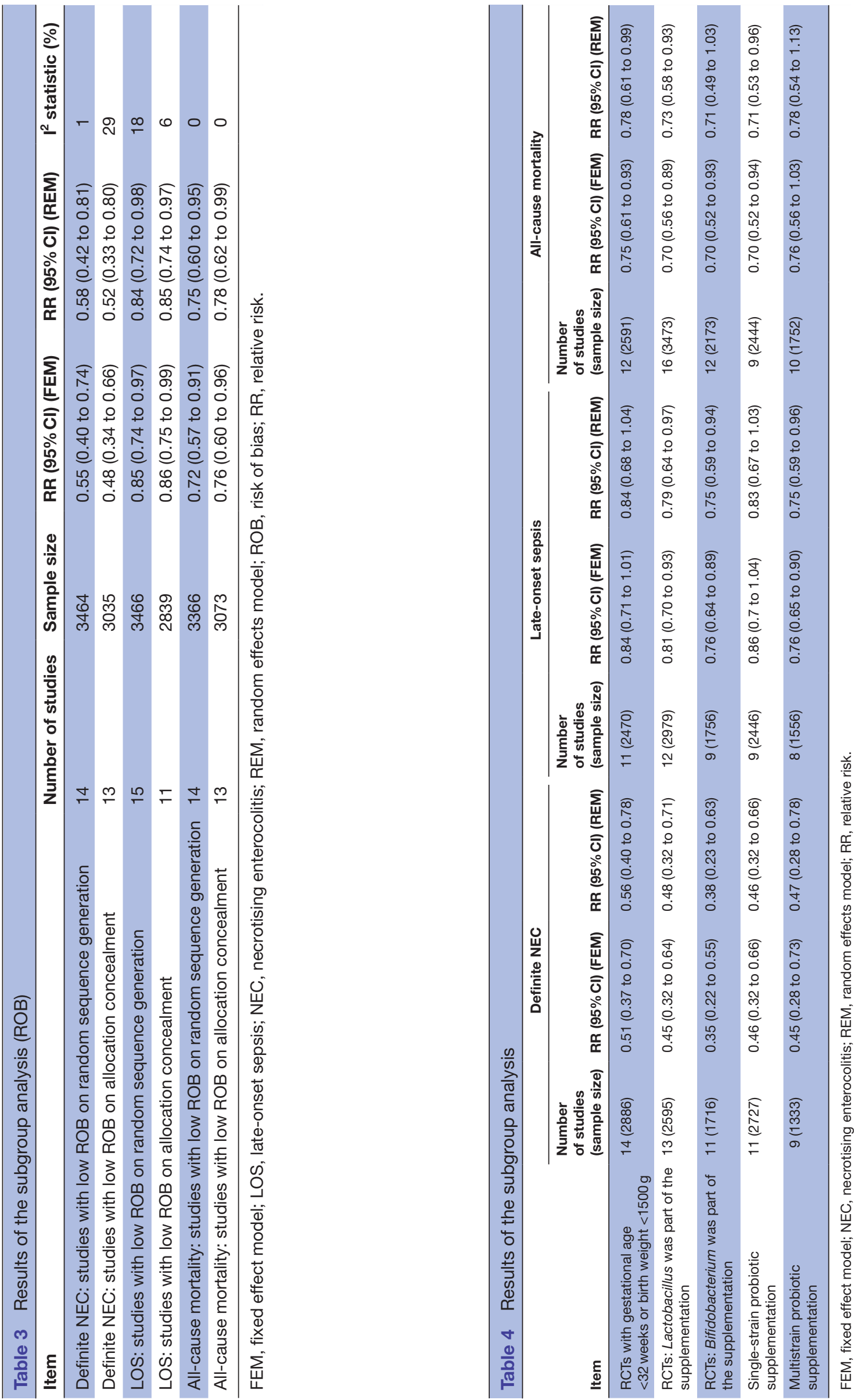

\begin{tabular}{l} 
W \\
\multirow{2}{c}{} \\
0 \\
0 \\
0 \\
\hline
\end{tabular} 
Table 5 Summary of findings as per GRADE guidelines ${ }^{38}$

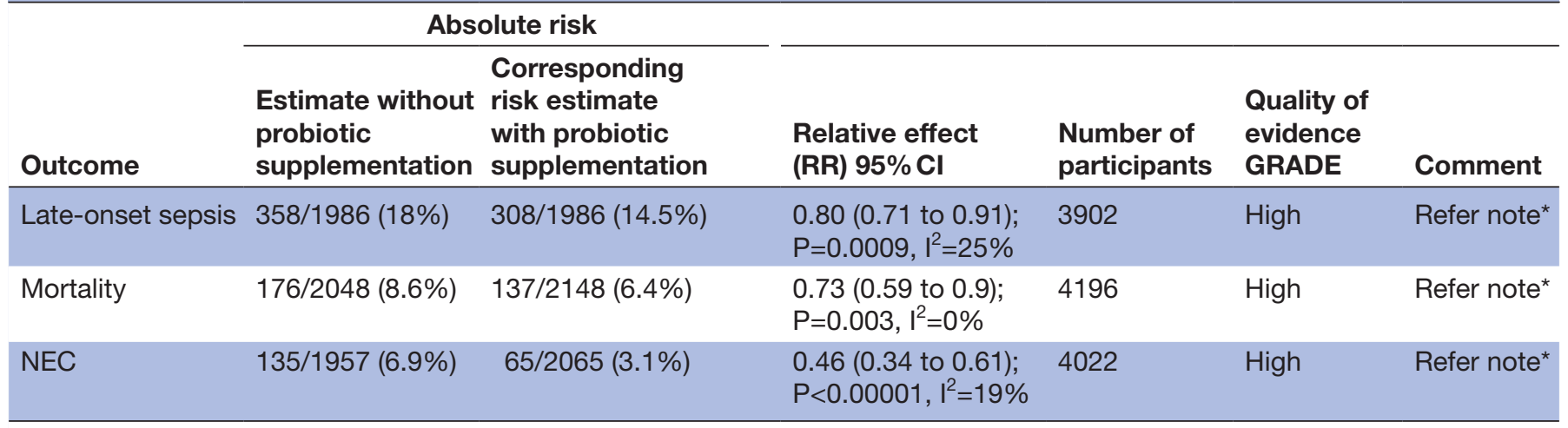

*Note: The evidence was deemed high in view of the large sample size, low risk of bias in majority (14/20) of the included studies, narrow Cls around the effect size estimate, very low $\mathrm{P}$ Value for effect size estimate and mild statistical heterogeneity.

GRADE, Grades of Recommendation, Assessment, Development and Evaluation; RR, relative risk.

The issue of implementing probiotics for preterm neonates in LMICs is complex. The options include either reconfirming their safety and efficacy in large definitive RCTs in LMICs or adopting their routine use based on current evidence. Conducting large multicentre trials and accessing proven safe and effective probiotics is difficult, especially in resource-limited set-ups. ${ }^{34}$ Apart from the significant budget, the difficulties include regulatory hurdles, logistics of importing a probiotic product, maintaining cold chain and providing ongoing independent safety and quality control. However, there are recent examples of large RCTs conducted successfully in community settings in LMICs. ${ }^{81-83}$ Neonatal demographic characteristics, such as gestation and IUGR, are an important issue in conducting RCTs in LMICs as they determine the risk of NEC, duration of probiotic supplementation and the cost-benefit ratio. It is also important to note that many RCTs have used different probiotic/s and probiotic activity could be strain specific.

Knowledge of the pattern of gut colonisation in preterm neonates in a given set-up is important before using probiotics for research or routine use. Dutta et al have reported abnormal intestinal colonisation patterns in the first week of life in VLBW neonates in their level

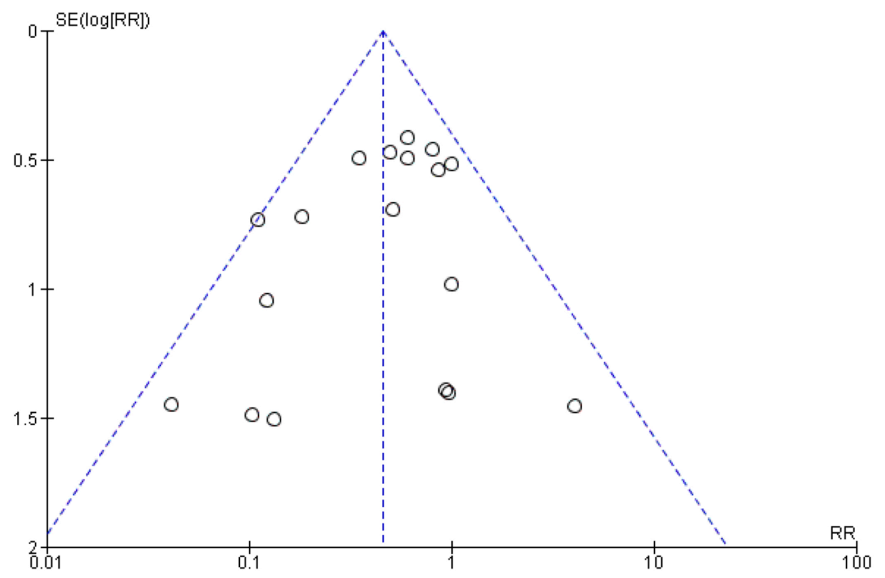

Figure 6 Funnel plot assessing publication bias. RR, risk ratio.
III neonatal intensive care unit in India. ${ }^{52}$ On day $1,45 \%$ neonates had sterile guts, and by day 3 , all were colonised predominantly by Escherichia coli, Klebsiella pneumoniae and Enterococcus faecalis. Only one isolate had lactobacilli and bifidobacteria were not detected during the study period. Formula feeding was associated with E. coli colonisation. Results of completed ${ }^{82}$ and ongoing trials such as NCT02552706 will be important. ${ }^{83}$

Probiotic sepsis, antibiotic resistance and altered immune responses in the long run are the potential adverse effects of probiotics in preterm neonates. Availability of killed or inactivated probiotic strains with clinically proven benefits may help in avoiding such adverse effects and in avoiding the need to maintain the cold chain. Awad et al have compared the effect of oral killed (KP) versus living Lactobacillus acidophilus (LP) in reducing the incidence of LOS and NEC in neonates. ${ }^{46}$ Both LP and KP reduced the risk of NEC (absolute risk reduction (ARR): $16 \%, 15 \%$, respectively) and LOS (ARR: 18\%) significantly compared with placebo. LOS and NEC was reduced significantly in neonates colonised versus not colonised by Lactobacillus at day 7 (27.9 vs $85.9 \%, 0$ vs $7.8 \%$ ) and day 14 (48.7 vs $91.7 \%$ for LOS and 0 vs $20.8 \%$ for NEC). KP retained the benefits similar to LP on comparison between all groups. Given the global implications of these results, the benefits of inactivated/ killed probiotics need to be assessed in further large definitive trials.

In summary, our results indicate that probiotics are effective in significantly reducing the risk of all-cause mortality, LOS and NEC in preterm VLBW neonates in LMICs. Considering the burden of death, disease (NEC, LOS) and suboptimal nutrition in preterm neonates in LMICs, cooperation between various stake holders (eg, industry, scientists, regulatory agencies) is warranted to either develop or to improve access to high-quality safe and effective probiotics in such set-ups. Support from organisations such as the WHO is important in providing access to probiotics for the countries (eg, sub-Saharan Africa) where most prematurity related deaths occur. 
Whether probiotics could be used for research and/or routine use in preterm neonates in LMICs will depend on the national health priorities, resources and ethics.

Contributors GD conceptualised and designed the study, performed an independent literature search, selected studies for inclusion, extracted and interpreted data, assessed risk of bias of included studies, handled the metaanalysis software, oversaw translation of manuscripts in the Chinese language and wrote the first and final drafts of the manuscript. GJ performed an independent literature search, selected studies for inclusion, contacted authors for additional information where necessary, extracted and interpreted the data, checked the data entered by GD on the meta-analysis software, assessed the risk of bias of included studies and helped with the first and the final draft of the manuscript. SR performed an independent literature search, selected studies for inclusion, verified the extracted data, assessed risk of bias, interpreted data and helped with the first and the final draft of the manuscript. SP supervised the project, acted as referee author in case of differences of opinion between the first three authors, interpreted the data and supervised the first and approved the final versions of the manuscript. All authors approved the final manuscript as submitted.

Funding Nepean Neonatal Intensive Care Parent Support Group (NNICUPS) Competing interests None declared.

Provenance and peer review Not commissioned; externally peer reviewed. Data sharing statement No additional data are available.

Open Access This is an Open Access article distributed in accordance with the Creative Commons Attribution Non Commercial (CC BY-NC 4.0) license, which permits others to distribute, remix, adapt, build upon this work non-commercially, and license their derivative works on different terms, provided the original work is properly cited and the use is non-commercial. See: http://creativecommons.org/ licenses/by-nc/4.0/

(c) Article author(s) (or their employer(s) unless otherwise stated in the text of the article) 2017. All rights reserved. No commercial use is permitted unless otherwise expressly granted.

\section{REFERENCES}

1. Liu L, Johnson HL, Cousens S, et al. Global, regional, and national causes of child mortality: an updated systematic analysis for 2010 with time trends since 2000. Lancet 2012;379:2151-61.

2. Oestergaard MZ, Inoue M, Yoshida S, et al. Neonatal mortality levels for 193 countries in 2009 with trends since 1990: a systematic analysis of progress, projections, and priorities. PLoS Med 2011;8:e1001080.

3. UNICEF. Committing to child survival: a promise renewed, progress report 2014 http://files.unicef.org/publications/files/APR_2014_web_ 15Sept14.pdf (accessed 26 Apr 2017).

4. Blencowe $\mathrm{H}$, Cousens $\mathrm{S}$. Addressing the challenge of neonatal mortality. Trop Med Int Health 2013;18:303-12.

5. Blencowe H, Cousens S, Chou D, et al. Born too soon: the global epidemiology of 15 million preterm births. Reprod Health 2013;10:S2.

6. Blencowe H, Cousens S, Oestergaard MZ, et al. National, regional, and worldwide estimates of preterm birth rates in the year 2010 with time trends since 1990 for selected countries: a systematic analysis and implications. Lancet 2012;379:2162-72.

7. Rüegger $C$, Hegglin M, Adams M, et al. Population based trends in mortality, morbidity and treatment for very preterm- and very low birth weight infants over 12 years. BMC Pediatr 2012;12:17.

8. Stoll BJ, Hansen NI, Bell EF, et al. Trends in care practices, morbidity, and mortality of extremely preterm neonates, 1993-2012. JAMA 2015;314:1039-51.

9. Arnold M, Moore SW, Sidler D, et al. Long-term outcome of surgically managed necrotizing enterocolitis in a developing country. Pediatr Surg Int 2010;26:355-60.

10. Katz J, Lee AC, Kozuki N, et al. Mortality risk in preterm and small-for-gestational-age infants in low-income and middle-income countries: a pooled country analysis. Lancet 2013;382:417-25.

11. Ramji S, Modi M, Gupta N. 50 years of neonatology in India, progress and future. Indian Pediatr 2013;50:104-6.

12. Samanta M, Sarkar M, Ghosh P, et al. Prophylactic probiotics for prevention of necrotizing enterocolitis in very low birth weight newborns. J Trop Pediatr 2009;55:128-31.

13. WHO, UNICEF. Every Newborn: an action plan to end preventable deaths. Geneva: World Health Organization, 2014. http://apps. who.int/iris/bitstream/10665/127938/1/9789241507448_eng.pdf (accessed 21 Jan 2017).

14. Guidelines for the Evaluation of Probiotics in Food: Report of a Joint FAO/WHO Working Group on Drafting Guidelines for the Evaluation of Probiotics in Food, 2002. http://www.fao.org/tempref/docrep/fao/ 009/a0512e/a0512e00.pdf (accessed 15 Jan 2017).

15. AlFaleh K, Anabrees J. Probiotics for prevention of necrotizing enterocolitis in preterm infants. Cochrane Database Syst Rev 2014;4:CD005496.

16. Deshpande G, Rao S, Patole S, et al. Updated meta-analysis of probiotics for preventing necrotizing enterocolitis in preterm neonates. Pediatrics 2010;125:921-30.

17. Lau CS, Chamberlain RS. Probiotic administration can prevent necrotizing enterocolitis in preterm infants: A meta-analysis. J Pediatr Surg 2015;50:1405-12.

18. Di Mauro A, Neu J, Riezzo G, et al. Gastrointestinal function development and microbiota. Ital J Pediatr 2013;39:15.

19. Ewaschuk JB, Diaz H, Meddings L, et al. Secreted bioactive factors from Bifidobacterium infantis enhance epithelial cell barrier function. Am J Physiol Gastrointest Liver Physiol 2008;295:G1025-34.

20. Garrido D, Barile D, Mills DA. A molecular basis for bifidobacterial enrichment in the infant gastrointestinal tract. Adv Nutr 2012;3:415S-21.

21. Rao RK, Samak G. Protection and restitution of gut barrier by probiotics: nutritional and clinical implications. Curr Nutr Food Sci 2013;9:99-107.

22. Walker A. Intestinal colonization and programming of the intestinal immune response. J Clin Gastroenterol 2014;48:S8-11.

23. Deshpande G, Rao S, Patole S. Probiotics in neonatal intensive care - back to the future. Aust N Z J Obstet Gynaecol 2015;55:210-7.

24. Härtel C, Pagel J, Rupp J, et al. Prophylactic use of Lactobacillus acidophilus/Bifidobacterium infantis probiotics and outcome in very low birth weight infants. J Pediatr 2014;165:285-9.

25. Janvier A, Malo J, Barrington KJ. Cohort study of probiotics in a North American neonatal intensive care unit. $J$ Pediatr 2014;164:980-5.

26. Li D, Rosito G, Slagle T. Probiotics for the prevention of necrotizing enterocolitis in neonates: an 8-year retrospective cohort study. J Clin Pharm Ther 2013;38:445-9.

27. Patole SK, Rao SC, Keil AD, et al. Benefits of Bifidobacterium breve M-16V supplementation in preterm neonates: a retrospective cohort study. PLoS One 2016;11:e0150775.

28. Repa A, Thanhaeuser M, Endress D, et al. Probiotics (Lactobacillus acidophilus and Bifidobacterium infantis) prevent NEC in VLBW infants fed breast milk but not formula [corrected]. Pediatr Res 2015;77:381-8.

29. Samuels N, van de Graaf R, Been JV, et al. Necrotising enterocolitis and mortality in preterm infants after introduction of probiotics: a quasi-experimental study. Sci Rep 2016;6:31643.

30. Viswanathan S, Lau C, Akbari H, et al. Survey and evidence based review of probiotics used in very low birth weight preterm infants within the United States. J Perinatol 2016;36:1106-11.

31. Luoto R, Isolauri E, Lehtonen L. Safety of Lactobacillus GG probiotic in infants with very low birth weight: twelve years of experience. Clin Infect Dis 2010;50:1327-8.

32. Sathoh $\mathrm{Y}$, Shinohara K, Umeazki $\mathrm{H}$, et al. Bifidobacteria prevents necrotising enterocolitis and infection. Int $\mathrm{J}$ Probiot Prebiot 2007;2:149-54

33. Applegate JA, Fischer Walker CL, Ambikapathi R, et al. Systematic review of probiotics for the treatment of community-acquired acute diarrhea in children. BMC Public Health 2013;13:S16.

34. Enos MK, Burton JP, Dols J, et al. Probiotics and nutrients for the first 1000 days of life in the developing world. Benef Microbes 2013;4:3-16.

35. Noratto G. Probiotics as a strategy to Improve overall human health in developing countries. J Probiotics Health 2014;02.

36. Sleator RD, Hill C. Probiotics as therapeutics for the developing world. J Infect Dev Ctries 2007;1:7-12.

37. Higgins J, Green S. Cochrane Handbook for Systematic Reviews of Interventions Version 5.1.0 [updated March 2011: The Cochrane Collaboration, 2011.

38. Dissemination CFRA. Systematic reviews: CRD's guidance for undertaking reviews in health care, 2009. http://www.york.ac.uk/crd/ guidance/ (accessed 21 Jan 2017)

39. Moher D, Altman DG, Liberati A, et al. PRISMA statement. Epidemiology (Cambridge, Mass). 2011;22:128.

40. The World Bank. Country and lending groups, 2015. http://data. worldbank.org/about/country-and-lending-groups\#Lower_middle_ income (accessed 16 Mar 2017).

41. Walsh MC, Kliegman RM. Necrotizing enterocolitis: treatment based on staging criteria. Pediatr Clin North Am 1986;33:179-201. 
42. Wang Q, Dong J, Zhu Y. Probiotic supplement reduces risk of necrotizing enterocolitis and mortality in preterm very low-birthweight infants: an updated meta-analysis of 20 randomized, controlled trials. J Pediatr Surg 2012;47:241-8.

43. Yang $\mathrm{Y}$, Guo $\mathrm{Y}, \mathrm{Kan} \mathrm{Q}$, et al. A meta-analysis of probiotics for preventing necrotizing enterocolitis in preterm neonates. Braz J Med Biol Res 2014;47:804-10.

44. Guyatt GH, Oxman AD, Santesso N, et al. GRADE guidelines: 12. Preparing summary of findings tables-binary outcomes. J Clin Epidemiol 2013;66:158-72.

45. Sterne JA, Egger M. Funnel plots for detecting bias in meta-analysis: guidelines on choice of axis. J Clin Epidemiol 2001:54:1046-55.

46. Awad H, Mokhtar H, Imam SS, et al. Comparison between killed and living probiotic usage versus placebo for the prevention of necrotizing enterocolitis and sepsis in neonates. Pak J Biol Sci 2010;13:253-62.

47. Braga TD, da Silva GA, de Lira PI, et al. Efficacy of Bifidobacterium breve and Lactobacillus casei oral supplementation on necrotizing enterocolitis in very-low-birth-weight preterm infants: a double-blind, randomized, controlled trial. Am J Clin Nutr 2011;93:81-6.

48. Dashti S, Seyyed A, Basiry A, et al. Prophylactic probiotics for prevention of necrotizing enterocolitis (nec) in low birth weight neonates. Arch Pediatr Infect Dis 2014:2:175-9.

49. Demirel G, Erdeve O, Celik IH, et al. Saccharomyces boulardii for prevention of necrotizing enterocolitis in preterm infants: a randomized, controlled study. Acta Paediatr 2013;102:e560-5.

50. Deng J, Chen K. Early minimal feeding combined with probiotics to prevent necrotizing enterocolitis in preterm infant. Chinese Journal of Modern Drug Application 2010;4:13-14.

51. Dilli D, Aydin B, Fettah ND, et al. The propre-save study: effects of probiotics and prebiotics alone or combined on necrotizing enterocolitis in very low birth weight infants. $J$ Pediatr 2015;166:545-51.

52. Dutta S, Ray P, Narang A. Comparison of stool colonization in premature infants by three dose regimes of a probiotic combination: a randomized controlled trial. Am J Perinatol 2015;32:733-40.

53. Fernández-Carrocera LA, Solis-Herrera A, Cabanillas-Ayón M, et al. Double-blind, randomised clinical assay to evaluate the efficacy of probiotics in preterm newborns weighing less than $1500 \mathrm{~g}$ in the prevention of necrotising enterocolitis. Arch Dis Child Fetal Neonatal Ed 2013;98:F5-9.

54. Hua XT, Tang J, Mu DZ. [Effect of oral administration of probiotics on intestinal colonization with drug-resistant bacteria in preterm infants] Zhongguo Dang Dai Er Ke Za Zhi 2014;16:606-9.

55. Huang B, Yang H, Huang X. Probiotics supplementation for prevention of necrotizing enterocolitis in very low-birth-weight neonates: a randomized, controlled trial. J Guangdong Med Coll 2009;27:37-9.

56. Oncel MY, Sari FN, Arayici S, et al. Lactobacillus reuteri for the prevention of necrotising enterocolitis in very low birthweight infants: a randomised controlled trial. Arch Dis Child Fetal Neonatal Ed 2014;99:F110-5.

57. Qiao $L$, Tang $Y$, Wang $W$, et al. The effects of probiotics supplementation on premature infants in NICU. Chin J Microbiol 2012;11:1011-3.

58. Rojas MA, Lozano JM, Rojas MX, et al. Prophylactic probiotics to prevent death and nosocomial infection in preterm infants. Pediatrics 2012;130:e1113-20.

59. Roy A, Chaudhuri J, Sarkar D, et al. Role of enteric supplementation of probiotics on late-onset sepsis by candida species in preterm low birth weight neonates: a randomized, double blind, placebocontrolled trial. N Am J Med Sci 2014;6:50-7.

60. Saengtawesin V, Tangpolkaiwalsak R, Kanjanapattankul W. Effect of oral probiotics supplementation in the prevention of necrotizing enterocolitis among very low birth weight preterm infants. J Med Assoc Thai 2014;97:S20-5.

61. Sari FN, Dizdar EA, Oguz S, et al. Oral probiotics: Lactobacillus sporogenes for prevention of necrotizing enterocolitis in very lowbirth weight infants: a randomized, controlled trial. Eur J Clin Nutr 2011;65:434-9.
62. Serce O, Benzer D, Gursoy T, et al. Efficacy of Saccharomyces boulardii on necrotizing enterocolitis or sepsis in very low birth weight infants: a randomised controlled trial. Early Hum Dev 2013;89:1033-6.

63. Shadkam M, Jalalizadeh F, Nasiriani K. Effects of probiotic lactobacillus reuteri (DSM 17938) on the Incidence of Necrotizing Enterocolitis in Very Low Birth Weight Premature Infants. Iran $\mathrm{J}$ Neonatol 2015;6:15-20.

64. Tewari VV, Dubey SK, Gupta G. Bacillus clausii for prevention of lateonset sepsis in preterm infants: a randomized controlled trial. $J$ Trop Pediatr 2015;61:377-85.

65. Van Niekerk E, Nel DG, Blaauw R, et al. Probiotics Reduce Necrotizing Enterocolitis Severity in HIV-exposed Premature Infants. $J$ Trop Pediatr 2015;61:155-64.

66. Yang S, Yi H, Gan B, et al. The clinical application value of endangered preterm infants given earlier amounts of micro feedings and adding probiotics. J Pediat Pharmacy 2011;17:21-4.

67. $\mathrm{Xu} \mathrm{L}, \mathrm{Wang} \mathrm{Y}$, Wang $\mathrm{Y}$, et al. A double-blinded randomized trial on growth and feeding tolerance with Saccharomyces boulardii CNCM I-745 in formula-fed preterm infants. J Pediatr 2016;92:296-301.

68. Gladstone M, Oliver C, Van den Broek N. Survival, morbidity, growth and developmental delay for babies born preterm in low and middle income countries - a systematic review of outcomes measured. PLoS One 2015;10:e0120566.

69. Beck S, Wojdyla D, Say L, et al. The worldwide incidence of preterm birth: a systematic review of maternal mortality and morbidity. Bull World Health Organ 2010;88:31-8.

70. Lawn JE, Gravett MG, Nunes TM, et al. Global report on preterm birth and stillbirth (1 of 7): definitions, description of the burden and opportunities to improve data. BMC Pregnancy Childbirth 2010;10:S1-22.

71. Rao SC, Athalye-Jape GK, Deshpande GC Simmer KN, et al. Probiotic supplementation and late-onset sepsis in preterm infants: a meta-analysis. Pediatrics 2016;137:1-16.

72. Sassone-Corsi M, Raffatellu M. No vacancy: how beneficial microbes cooperate with immunity to provide colonization resistance to pathogens. J Immunol 2015;194:4081-7.

73. Hammerman C, Kaplan M. Probiotics and neonatal intestinal infection. Curr Opin Infect Dis 2006;19:277-82.

74. Ashraf R, Shah NP. Immune system stimulation by probiotic microorganisms. Crit Rev Food Sci Nutr 2014;54:938-56.

75. Hardy H, Harris J, Lyon E, et al. Probiotics, prebiotics and immunomodulation of gut mucosal defences: homeostasis and immunopathology. Nutrients 2013;5:1869-912.

76. Thaver D, Zaidi AK. Burden of neonatal infections in developing countries: a review of evidence from community-based studies. Pediatr Infect Dis J 2009;28:S3-9.

77. Qazi SA, Stoll BJ. Neonatal sepsis: a major global public health challenge. Pediatr Infect Dis J 2009;28:S1-2.

78. Neu J, Walker WA. Necrotizing enterocolitis. N Engl J Med 2011;364:255-64.

79. Mwansa-Kambafwile J, Cousens S, Hansen T, et al. Antenatal steroids in preterm labour for the prevention of neonatal deaths due to complications of preterm birth. Int J Epidemiol 2010;39:i122-33.

80. Lee AC, Katz J, Blencowe $\mathrm{H}$, et al. National and regional estimates of term and preterm babies born small for gestational age in 138 lowincome and middle-income countries in 2010. Lancet Glob Health 2013;1:e26-36.

81. Sinha A, Gupta SS, Chellani H, et al. Role of probiotics VSL\#3 in prevention of suspected sepsis in low birthweight infants in India: a randomised controlled trial. BMJ Open 2015;5:e006564.

82. Panigrahi P, Parida S, Nanda NC, et al. A randomized synbiotic trial to prevent sepsis among infants in rural India. Nature 2017:548:407-12.

83. ClinicalTrials.gov [Internet]. The Efficacy and Mechanisms of Oral Probiotics in Preventing Necrotizing Enterocolitis. Bethesda (MD): National Library of Medicine (US). 2000 Feb 29- Identifier NCT025552706, [about 4 screens], 2015. https://clinicaltrials.gov/ ct2/show/record/NCT02552706?term=probiotics\&recr=Open\&rank= 23 (accessed 21 Apr 2017). 